http://heanoti.com/index.php/hn

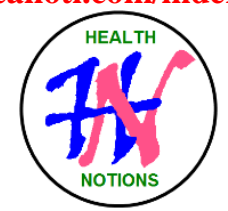

LITERATURE REVIEW ARTICLE

URL of this article: http://heanoti.com/index.php/hn/article/view/hn30101

\title{
Knowledge Translation, A Challenge in Nursing Practice in The 21st Century
}

Tanko Titus Auta ${ }^{1(\mathrm{CA})}$

Ministry of Health, College of Nursing, School of Midwifery, Minna, Nigeria / St. Paul University, Cagayan, Philippines; tomatitus0@gmail.com/autatk@yahoo.com (Corresponding Author)

\begin{abstract}
Health care systems are experiencing challenges of improving the quality of care and decreasing the risk of adverse events health consumers are likely to be exposed to globally. Nursing, as a social and humanistic discipline is structured within the care process, is interrelated with the phenomena of the experienced world in which the other cohabits. As the profession expands it body of knowledge based on elements from nursing practices, it has to develop instruments that qualify its care process, such as classifications that seek to diagnose, foresee results and define interventions in the health and disease process. Research has shown that proven effective intervention now exist that would enable all countries to meet the health care challenges through improvement in evidence based practice as a result of the introduction of knowledge translation in the health sector. It is believed that studies on knowledge translation are absorbed in practice, but more robust designs are needed to put these results into practice, with consequent benefits for health teams, patients and family members. Care is however required to avoid the knowledge translation imperative that would give a translational perspective to nursing research.
\end{abstract}

Keywords: Evidence based practice, Knowledge translation, Quality care

\section{INTRODUCTION}

Health care systems are experiencing challenges of improving the quality of care and decreasing the risk of adverse events that the health consumers are likely to be exposed to globally. Knowledge translation is the process of moving what has been learned through research to the actual applications of knowledge in a variety of practice settings and circumstances ${ }^{(1),(2)}$. Knowledge translation (KT) is a complex and multidimensional concept that demands a comprehensive understanding of its mechanisms, methods, and measurements, as well as of its influencing factors at the individual and contextual levels and the interaction between both those levels ${ }^{(3)}$. This know-do gap is considered one of the most important challenges for public health in this century $^{(1),(4)}$

Translation science is a rapidly growing area of investigation and because health systems fail to optimally utilized it with resulting inefficiencies and reduced quantity and quality of life ${ }^{(5),(6),(7)}$, and cited an example where ${ }^{(8)}$ found that USA adults received less than $55 \%$ of recommended care ${ }^{(9)}$. Collaborate the view of $^{(5)}$ that a number of healthcare practices have an evidence-base but they are not yet a part of routine care hence the gap between the availability of evidence and application in care delivery contributes to poor health outcomes. As important as providing evidence from clinical research e.g. through publication in journals or presentation at scientific meetings is, it is not sufficient for the provision of optimal care or decision making for patient's health satisfaction. The real science and practice of knowledge translation is therefore needed to overcome these challenges towards achieving quality care. To remedy and overcome these challenges, ${ }^{(5)}$ pointed out that the growing emphasis on knowledge translation has led to the establishment of an interdisciplinary field of research. Therefore knowledge translation, research, and enhanced capacity in this field are concomitantly essential if we are to reap the benefits of health research, improve health and quality of life, and enhance productivity. This article is not intended to be an in-depth or systematic review of any one aspect of knowledge translation; rather, it is designed to elicit the aspects of challenges nurses encountered in the practice area for the purpose of raising awareness, connecting thoughts and perspectives, and stimulating ideas and questions about knowledge translation for future research of this area of inquiry in rehabilitation.

Knowledge translation is the use of knowledge in practice and decision making by the public, patients, health care professionals, managers, and policy makers ${ }^{(5)}$. Knowledge translation is a process in which through a set of challenging activities a body of knowledge is refined and implemented in a participatory context and led to efficient changes in quality of patient care, professional practice, healthcare system and community, and that expected changes will happen when the knowledge is gathered from multiple resources, the context is receptive, 
and the system is prepared. Therefore one can conclude that Knowledge translation is a dynamic and iterative process that includes synthesis, dissemination, and exchange as well as ethically-sound application of knowledge to improve the quality of healthcare to people, provide more effective health services and products and strengthen the health care system. Knowledge Creation will include knowledge inquiry, knowledge synthesis, and knowledge tools/products ${ }^{(10)}$.

Khoddam et al. ${ }^{(10)}$ in ${ }^{(6),(11),(12),(13),(14),(15),(16)}$ states that Knowledge Translation is a concept first used in 2000 by Grol \& Grimshaw ${ }^{(17)}$ to address the gap between research knowledge and its application in clinical practice in health. And since that time, the use of the term has grown dramatically, with a tenfold increase revealed by a search of Medline from 1990-2006. Although KT is widely used according to Khoddam et al. in (14),(18),(19), there is a plethora of other terms that have been used interchangeably in the literature e.g. knowledge transfer, research utilization, evidence implementation.

Environmental changes according to Stern et al. ${ }^{(20)}$ have affected things, people, value, and disease pattern globally and in consequence, people look for save heaven to overcome some of this phenomenon especially the one that affect health of individual. Stern et al. ${ }^{(20)}$ further stated that others have migrated or changed their ways of living as polar ice advanced and retreated, or endured crop failures or altered their crops when temperature and rainfall patterns changed. As a result, they made numerous other adjustments in individual and collective behavior. Stern et al. ${ }^{(20)}$ further stated that many human actions affect what people value. One way in which the actions that cause global changes continue Stern et al. ${ }^{(20)}$ are different from most of those that the effects take decades to centuries to be realized. And that this fact causes many concerned people to consider taking action now, to protect the values of those who might be affected by global environmental change in years to come. But that because of uncertainty about how global environmental systems work, and because the people affected will probably live in circumstances very much different from those of today and may have different values, it is hard to know how present-day actions will affect them ${ }^{(21)}$.

This change has coincided with the rapid marketization of health care provision, leading to dramatic declines in access and affordability or quality of health care among others. It has caused changes in the lifestyle and consequent health conditions of different populations. These aspects have likewise required areas of health in the domestic and international realm to create specific technologies aimed at providing effective health care. Crossetti \& de Góes ${ }^{(22)}$ pointed out those Constant transformations in the world resulting from social, political and economic determinants, among others, have caused changes in the lifestyle and consequent health conditions of different populations. These aspects have likewise required areas of health in the domestic and international realm to create specific technologies aimed at providing effective health care. This scenario has led to search of new knowledge to proffer solution to the emerging phenomenon. The knowledge though still in toddler stage is necessary for the benefits of human kind. According to Brown ${ }^{(23)}$ in ${ }^{(24)}$, there is differences between the "science" and the "practice" of knowledge translation, implying that the important of knowledge translation experiences is still staying hidden because their publication does not conform to the traditional research paradigm.

In any case, knowledge translation is still the common innovations health professionals need to improve the healthcare system. However, the production of this knowledge has been continuous and rapidly occurring at the same pace as the need emerges to provide health care to the population in different levels and contexts, a fact that has led to it being studied. Many of these innovations according Stern et al. ${ }^{(20)}$ first originated in wealthy countries, and have made it possible for the world to be responsible for producing the global public goods of medical and health-related research as well as development from which everyone has benefited, in poor and now-rich countries alike".

Nursing, as a social and humanistic discipline, where its being, knowing and doing is structured within the care process, is interrelated with the phenomena of the experienced world in which the other cohabits and, in light of these transformations, there is need to identify and to adapt its ways of providing care ${ }^{(22)}$. Says Crossetti $\&$ de Góes ${ }^{(22)}$, this is a condition in which movements are revealed, in the pursuit of specific knowledge through studies and research based on questions raised and the search for in the practice of nursing. There is need for nursing profession to embrace this opportunity (innovation in knowledge translation) because of the tremendous benefits the patient and the community members will gain from its application. When answers to phenomena are known, they have a great deal in evidence-based nursing practice because of the satisfaction that will benefit the health consumer. These include the construction of conceptual theoretical models to guide this doing process, as well as the appropriation of knowledge from other disciplines to enhance the care given to the patients. As a matter of fact, the realities of health care systems are that there are insufficient resources to do everything, and thus, all our hands must be on desk to work with stakeholders (including patients/public, clinicians, and policy makers) to establish an explicit prioritization process for knowledge translation activities to meet up with $21 \mathrm{st}$ century health challenges.

Despite widespread focus on quality in the healthcare sector as presented by Davis et al. ${ }^{(6)}$, performance reports highlight the need to improve the organization, delivery, and outcomes of healthcare services and programs. KT is one of the approaches for now that will greatly improve the healthcare and its outcomes by 
promoting and supporting the use of research in clinical, management, and policy-level decision-making. According to Khoddam et al. ${ }^{(10)}$, KT includes knowledge transfer or dissemination, or unidirectional sharing of research through mechanisms such as publications or presentations. Khoddam et al. ${ }^{(10)}$ in ${ }^{(12)}$ stated that KT also includes knowledge exchange, which refers to multidirectional interaction among researchers and decision makers for the conduct of research, program planning, evaluation, or quality improvement. While Canadian Institute of Health Research ${ }^{(11)}$ believe that KT is a complex, multi-step, cyclical process that involves synthesizing evidence and creating knowledge products; interacting with target users to assess needs; and identify barriers; using that information to tailor evidence syntheses or knowledge products; select implementation strategies; applying implementation strategies; monitoring to evaluate impact and ensure that research use is sustained. Straus et al. ${ }^{(13)}$ in ${ }^{(1)}$ on the other hand refers to KT as an evolving science that builds on theory and approaches from other disciplines to generate evidence on factors that has influence research use, or on approaches, strategies and interventions that effectively support research use. Little wonder, KT is a practice that can be applied by those interested in implementing newly generated evidence, or improving healthcare and its outcomes by promoting use of existing evidence.

\section{THE KNOWLEDGE TRANSLATION IN NURSING PRACTICE}

\section{Characteristics of Knowledge Translation}

As outline by The National Center for the Dissemination of Disability Research ${ }^{(12)}$ in ${ }^{(17)}$, a prominent characteristic of KT is that it encompasses all steps between the creation of new knowledge and its application to yield beneficial outcomes for society. Therefore KT is an interactive process underpinned by effective exchanges between researchers who create new knowledge and those who use it. Referring to Grol \& Grimshaw $^{(17)}$, KT is of the view that bringing users and creators of knowledge together during all stages of the research cycle is fundamental to successful KT.

While Grol \& Grimshaw ${ }^{(17)}$ pointed out that because Knowledge in KT has an implicit meaning as research-based knowledge, The National Center for the Dissemination of Disability Research ${ }^{(12)}$ envisioned that KT strategies can help define research questions and hypotheses, select appropriate research methods, conduct the research itself, interpret and contextualize the research findings as well as apply the findings to resolve practical issues and problems. Referring Grol \& Grimshaw ${ }^{(17)} \mathrm{KT}$ is of the view that continuing dialogues, interactions, and partnerships within and between different groups of knowledge creators and users for all stages of the research process should be integral parts of KT. The National Center for the Dissemination of Disability Research $^{(12)}$ present examples of different interactive groups to include: (a) Researchers within and across research disciplines; (b) Policymakers, planners, and managers throughout the health-care, public-health, and health public-policy systems; (c) Health-care providers in formal and informal systems of care; (d) General public, patient groups, and those who help to shape their views and/or represent their interests, including the media, educators, nongovernmental organizations, and the voluntary sector; and (e) The private sector, including venture capital firms, manufacturers, and distributors.

The National Center for the Dissemination of Disability Research ${ }^{(12)}$ in ${ }^{(17)}$ analyzed that the process of KT includes knowledge dissemination, communication, technology transfer, ethical context, knowledge management, knowledge utilization, two-way system where there is exchange between researchers and those who apply knowledge, implementation research, technology assessment, synthesis of results with the global context, and development of consensus guidelines. And that KT appears to be a larger construct that encompasses most previously existing concepts related to moving knowledge to use. Similarly, The National Center for the Dissemination of Disability Research ${ }^{(12)}$ in ${ }^{(17)}$ believe that KT is the newest conceptual development that seems to be more comprehensive, more sophisticated, and highly embedded in the actual contexts in which the knowledge applications will eventually occur. To this end, The National Center for the Dissemination of Disability Research ${ }^{(12)}$ in ${ }^{(17)}$ summarized in a non-ranked order the overall characteristics of KT as follows: (a) KT includes all steps between the creation of new knowledge and its application; (b) KT needs multidirectional communications; (c) KT is an interactive process; (d) KT requires ongoing collaborations among relevant parties; (e) KT includes multiple activities; (f) KT is a nonlinear process; (g) KT emphasizes the use of research-generated knowledge (that may be used in conjunction with other types of knowledge); (h) KT involves diverse knowledge-user groups (i) KT is user and context-specific; (j) KT is impact-oriented; and (k) $\mathrm{KT}$ is an interdisciplinary process.

\section{Importance of knowledge Translation (KT) in Nursing Practice}

It is the era we have named the age of the health consumer satisfaction. As nursing expands it body of knowledge based on elements from nursing practices, it has to develop instruments that qualify its care process, such as classifications that seek to diagnose, foresee results and define interventions in the health and disease process. As the review shows a change in quality of care, professional practice, health care systems, and community are the main outcomes of the KT process as identified in the literature. KT attempts to promote the 
health professions by growing the awareness and professional behavior of practitioners, and tries to improve the quality of care and patient outcomes by integrating knowledge into caring ${ }^{(10)}$. Hence there is need to conduct research/studies on the phenomena inherent on knowledge translation which will impart a translational character to such research, by inserting the producers (research nurses) and consumers (nurses providing care, patients and family members) into the construction of the studies, thus providing safe care that puts findings into practice. Khoddam et al. ${ }^{(10)}$ further posits that in addition, it plans to improve the health System through improving the organizational efficacy and informing policies and decisions. Ultimately, at community level, a successful KT process can cause a facilitated access to health services, cost reduction, equity in resource allocation, poverty reduction, and improvement in quality of life ${ }^{(10)}$. More so, now more than ever, hospitals need to serve and retain patients to stay in the black because patient consumers have much more choice than before. Besides, today knowledge is considered the most important assets of organization ${ }^{(10)}$, and it is assumed that every experience is revisable ${ }^{(10)}$. There is need for Organizations to make its efforts to get the appropriate and the right quality of knowledge needed for the effective performance of the various work roles in an organization.

Again, it boils down to closing the gap between KT and the healthcare business and fully understanding how this ties in to the patient experience and care continuum. The reality is inefficient KT can impact all aspects of the business from extra support costs, billing, purchasing, process improvement to medication delivery, surgery scheduling and literally everything in between. On the other hand, efficient KT in technology translates to things like enabling physicians to sign off on charts at home instead of having to perform these tasks on site. The example of increased efficiency through technology results in minimized operational costs, more work-life balance to the clinician and better care for the patient. The development can sustained synergy among knowledge users and knowledge producers, and the emancipation of post-positivist biomedical paradigms, removal of interdisciplinary barriers, and the development of sectors favoring a collective approach to shared problems and questions concerning health.

\section{Knowledge Translation and Evidence-Based Practice and Health Improvement}

Research has shown that proven effective intervention now exist that would enable all countries to meet the health care challenges through improvement in evidence based practice as a result of the introduction of knowledge translation in the health sector. Global debate according to $\mathrm{WHO}^{(4)}$ continues on how this gap can be further bridged. $\mathrm{WHO}^{(4)}$ further stated that evidence-based medicine and health policy represent genuine efforts to ensure that the best evidence informs policy and practice, but much remains to be done. $\mathrm{WHO}^{(4)}$ further stated that developing countries are underrepresented in randomized controlled trials and systematic reviews. This under-representation continue the author, contributes to the mismatch between best evidence and what is relevant, applicable, feasible and affordable in such countries; and that the situation is even more tenuous beyond the clinical setting, given the complex nature of public health and policy, where questions rarely lend themselves to traditional research approaches ${ }^{(4)}$.

Straus et al. ${ }^{(5)}$ in ${ }^{(25)}$ opined that failures to use research evidence to inform decision making are apparent across all key decision-maker groups, including health care providers, patients, informal careers, managers, and policy makers, in developed and developing countries, and in care provided by all disciplines. And that practice audits performed in a variety of settings have revealed that high-quality evidence is not being consistently applied in practice. Straus et al. ${ }^{(5)}$ pointed out in ${ }^{(26)}$, that although several randomized trials have shown that statins can decrease the risk of mortality and morbidity in post stroke patients, statins are considerably under prescribed. In contrast, continue Straus et al. ${ }^{(5)}$ in ${ }^{(27),(28),(29)}$, antibiotics are overprescribed in children with upper respiratory tract symptoms. A synthesis of 14 studies showed that many patients (26-95\%) were dissatisfied with information given. Lavis et al. ${ }^{(27)}$ studied eight health policy-making processes in Canada, and concluded that citable health services research was used in at least one stage of the policy-making process for only four policies, and only one of these four policies had citable research used in all stages of the policy-making process. Similarly, evidence from systematic reviews was not frequently used by World Health Organization policy makers $^{(5)}$ in $^{(30)}$.

Increasing recognition of these issues has led to attempts to affect behavior, practice, or policy change. According to Straus et al. ${ }^{(5)}$ in ${ }^{(6)}$, changing behavior is a complex process requiring evaluation of the entire health system, including systematic barriers to change (such as lack of integrated health information systems), and targeting of all those involved in decision making including clinicians, policy makers, and patients. Therefore efforts must be made to close the knowledge-to-practice gaps by effective knowledge translation interventions and thereby improve health outcomes. The initiative must cover all aspects of care including access to and implementation of valid evidence in the organizational and for the systems issues.

As the review shows a change in quality of care, professional practice, health care systems, and community are the main outcomes of the KT process as identified in the literature. Undoubtedly as opined by Khoddam et al. ${ }^{(10)}$, KT is the most comprehensive approach to applying knowledge to action because it addresses all influential fields on health. KT attempts to promote the health professions by growing the 
awareness and professional behavior of practitioners, and tries to improve the quality of care and patient outcomes by integrating knowledge into caring as well as plan to improve the health System through improving the organizational efficacy and informing policies and decisions. Ultimately, at community level, a successful KT process can cause a facilitated access to health services, cost reduction, equity in resource allocation, poverty reduction, and improvement in quality of life ${ }^{(10)}$. In fact the final consequence of all these changes in the real sense is the general health improvement.

\section{Challenges in Knowledge Translation}

According to Khoddam et al. ${ }^{(10)}$, KT is a dynamic process involving a permanent interaction with the context and users. Moreover, continuous interaction with potential users and setting the activities based on their needs is critical because different groups of people participate in the process. These groups include knowledge producers, knowledge facilitators, and knowledge users from different levels such as patients, health care practitioners, managers, decision makers, and policymakers. Applying a unique strategy, facilitating interaction among groups, and convincing them to practice and make a decision based on the evidence on the one hand, and continuous evaluation to support the sustainability of located changes and desired outcomes on the other hand make the process challenging. In this way, keeping the process congruent with legal frameworks, ethical principles and social norms and values is critical too.

\section{Mentorship of Knowledge Translation in Healthcare}

Wong et al. ${ }^{(31)}$ mentioned that mentorship is an interactive, facilitative process meant to promote learning and development that is based on educational and social learning theories as well as within the context of large corporations where it is used for training, professional development, and succession planning. As pointed out by the Wong et al. ${ }^{(31)}$, in seminal research mentoring has largely been studied in the context of academic medicine where physician trainees or junior physician investigators are mentored by those more experienced for career and personal development and it was found that mentoring consists of significant benefits to mentorship where the mentees receive more promotions, have higher salaries, experience less stress and conflict, are more satisfied with their jobs and clients and are less likely to leave their organizations compared with non-mentees as well as the mentors deriving benefits from mentoring including satisfaction from helping others, creation of free time for alternate pursuits, organizational recognition or reward, and improved job performance through exposure to new idea; are of the view that a systematic review of academic mentoring in nursing was associated with greater job satisfaction and academic achievement. In view of the forgoing discussions, it will be advisable that strategies to enhance mentorship should be a development both in formal and informal mentorship initiatives, and mentorship training for mentors and mentees should be encouraged especially academic mentorship of student and novice nurses. Also institutions of higher learning should include mentoring program in their curriculum.

\section{Ethics and scholarly integrity in Knowledge Translation}

Page \& Nyeboer ${ }^{(32)}$ analyzed that instances of research misconduct and abuse of research participants informed the need for research ethics oversight to protect the rights and welfare of study participants as well as the integrity of the research enterprise. As a result, national and international regulations have emerged that are intended to protect research participants, hence it is the responsibility of Research Ethics Boards (REBs)/Institutional Review Boards (IRBs) and Research Ethics Committees (RECs) to ensuring that research is planned and conducted in accordance with such laws and regulatory standards. A good researcher should try to avoid any bias. To avoid COIs' influence on your academic work, mentoring supervisor in researchers should provide a transparency disclosure which lists those external factors related to their work.

\section{Technology and Its Impact}

Technology has changed society throughout history. Over the last few decades, cellular devices, iPads, iPods, computers, and most importantly the internet have completely overhauled the way people interact in society and the way educators work in schools. Technology has changed the way society looks and can greatly improve these lines of communication hence it should be inclusive during the mentoring process due to the changing times and high demands for tech savvy personnel; ${ }^{(33)}$ is of the view that teachers of the 21 st century adjust to the technological revolution and not only prepare themselves but prepare their students for the technological real world. The 21 st century society demands a technologically advanced person and the 21 st century knowledge translation requires the same. 


\section{Obstacle or Challengers facing implementation of Knowledge Translation}

For KT to be a reality in health practices according to Crossetti \& de Góes ${ }^{(22)}$, certain obstacles also need to be overcome, such as: familiarization with knowledge translation, identification of relevant research problems, expansion of the partnership between researchers and users of knowledge, development and application of KT models, inclusion of KT in research budgets, quality of clinical research ${ }^{(34)}$, accuracy of interventions and reliability of data ${ }^{(26)}$. Others includes; Individual staff nurse interest in research and the degree to which each nurse is involved in reading research regularly, Nurses' behaviors (their personal attributes), and interpersonal factors within their organizations, individual nurses' perceptions of potential criticism by staff colleagues, Educational interventions for evidence-based practice associated with lower research utilization. Interaction between researchers (research nurses) and users (nurses providing care) is a basic characteristic of KT that varies in intensity, complexity and level of engagement, as well as the importance of the context (physical, structural, organizational and social factors) ${ }^{(35)}$; and users who utilize the knowledge generated by research to make decisions upon which health policies, programs and/or practices will be based ${ }^{(17)}$.

In the context of strengthening health systems in developing countries, it is timely to revisit basic conceptions of evidence, information and knowledge. Beyond research and the various sources of useful knowledge continue, the key challenge lies in understanding the steps and processes involved in decisionmaking and implementation ${ }^{(4)}$. These according to $\mathrm{WHO}^{(4)}$, are complex and influenced by many factors including the user's context, the presence (or lack) of an enabling environment, perceived relevance and type of knowledge in question. $\mathrm{WHO}^{(4)}$ went further to say that linear, push-pull models imply that knowledge is a commodity that flows along a simple gradient from one group to another. More interactive models account for the complexity of individual reasoning and how groups of people solve problems ${ }^{(4)}$. In order to bridge the knowdo gap, there is need to better understand the means by which knowledge is translated into action for overall goal achievement. In addition to these fundamental aspects for the action of KT, Crossetti \& de Góes ${ }^{(22)}$ suggested that specific models should be apply to guide adequate use of research findings in professional practices. While (36) narrated that one literature review identified 28 different KT models, with the following common elements: identification of the problem and establishment of communication channels between users and researchers, development and selection of the type of research, analysis of the context, carrying out of activities or interventions for knowledge translation and application of the results in practice.

\section{CONCLUSION}

KT is a process through which set of challenging activities a body of knowledge is refined and implemented into a participatory context. The reality is that health care systems have insufficient resources to do everything, and thus, efforts must be made to work with stakeholders (including patients/public, clinicians, and policy makers) to establish an explicit prioritization process for knowledge translation activities as stated by Straus et al. ${ }^{(5)}$. It is believed that some of these studies are absorbed in practice, but more robust designs are needed to put these results into practice, with consequent benefits for health teams, patients and family members. This, however, among other aspects, will include the public, clinicians, and policy makers among others. Care is required to avoid the knowledge translation imperative that all knowledge must be translated into action as part of the study planning process that would give a translational perspective to nursing research.

\section{REFERENCES}

1. Carroll A, Toth-Cohen S. Cross-Cultural and Inter-Professional Knowledge Translation of Developmentally Supportive Care in an Indian NICU. Jefferson School of Health Professions, Thomas Jefferson University; 2017.

2. Sudsawad P. Knowledge Translation: Introduction to Models, Strategies and Measures. Austin, TX: Southwest Educational Development Laboratory: National Center for the Dissemination of Disability Research [NCDDR]; 2007.

3. Sudsawad P. Knowledge Translation: Introduction to Models, Strategies, and Measures. The University of Wisconsin-Madison: The National Center for the Dissemination of Disability Research; 2007.

4. WHO. Knowledge Translation in Global Health. Geneva: WHO; 2006.

5. Straus SE, Tetroe JM, Graham ID. Knowledge Translation is the Use of Knowledge in Health Care Decision Making. Journal of Clinical Epidemiology. 2011;64(1):6-10.

6. Davis D, Evans M, Jadad A, Perrier L, Rath D, Ryan D. et al. The Case for KT: Shortening the Journey from Evidence to Effect. BMJ. 2003;327:33-35.

7. Madon T, Hofman KJ, Kupfer L, Glass RI. Public Health. Implementation Science. Science. 2007;318:1728-1729.

8. McGlynn EA, Asch SM, Adams J, Keesey J, Hicks J, DeCristofaro A. et al. The Quality of Health Care Delivered to Adults in the US. N Engl J Med. 2003;348:2635-2645. 
9. Titler MG. Translation Research in Practice: An Introduction. OJIN: The Online Journal of Issues in Nursing. 2018;23(2).

10. Khoddam H, Mehrdad N, Peyrovi H, Kitson AL, Schultz TJ, Athlin AM. Knowledge Translation in Health Care: A Concept Analysis. Med J Islam Repub Iran. 2014;28(98).

11. Canadian Institute of Health Research. Knowledge Translation [Internet]. Ottawa: The Institute. 2016 [cited 2017 Jun 14]. Available from: http://www.cihr-irsc.gc.ca/e/29418.html\#1

12. The National Center for the Dissemination of Disability Research. Center on Knowledge Translation for Disability and Rehabilitation Research (KTDRR). 2007.

13. Straus SE, Tetroe J, Graham I. Defining Knowledge Translation. CMAJ. 2009;181(3-4):165-168.

14. Graham ID, Logan J, Harrison MB, Straus S, Tetroe J, Caswell W. et al. Lost in Knowledge Translation: Time for a Map? Journal of Continuing Education in the Health Professions. 2006;26(1):13-24.

15. Armstrong R, Waters E, Roberts H, Oliver S, Popay J. The Role and Theoretical Evolution of Knowledge Translation and Exchange in Public Health. Journal of Public Health. 2006;28(4):384-3899.

16. Tetroe J. Knowledge Translation at the Canadian Institutes of Health Research: A Primer. NCCDR FOCUS Technical Brief NO18; 2007.

17. Grol R, Grimshaw J. From Best Evidence to Best Practice: Effective Implementation of Change in Patients' Care. The Lancet. 2003;362(9391):1225-1230.

18. Davison CM. Knowledge Translation: Implications for Evaluation. New Directions for Evaluation. 2009;2009(124):75-87.

19. Larkin GL, Hamann CJ, Monico EP, Degutis L, Schuur J, Kantor W. et al. Knowledge Translation at the Macro Level: Legal and Ethical Considerations. Academic Emergency Medicine. 2007;14(11):1042.

20. Stern PC, Young OR, Druckman D. Global Environmental Change: Understanding the Human Dimensions. 1992.

21. Van der Vet PE, Nijveen H. Propagation of Errors in Citation Networks: A Study Involving the Entire Citation Network of A Widely Cited Paper Published in, and Later Retracted from, the Journal Nature. Research Integrity and Peer Review. 2016;1(3).

22. Crossetti MGO, de Góes MGO. Knowledge Translation: A Challenge in Providing Nursing Care: Rev. Gaúcha Enferm. 2017;38(2).

23. Brown GP. Challenges in Knowledge Translation: The Early Years of Cancer Care Ontario's Program in Evidence-Based Care. Curr Oncol. 2012;19(1):27-35.

24. Levine M, Browman G, Newman T, Cowan DH. The Ontario Cancer Treatment Practice Guidelines Initiative. Oncology (Williston Park). 1996;10(suppl):19-22.

25. Majumdar SR, McAlister FA, Furberg CD. From Knowledge to Practice in Chronic Cardiovascular Disease: A Long and Winding Road. J Am Coll Cardiol. 2004;43:1738-1742.

26. LaRocca R, Yost J, Dobbins M, Ciliska D, Butt M. The Effectiveness of Knowledge Translation Strategies Used in Public Health: A Systematic Review. BMC Public Health. 2012;12(751).

27. Lavis JN, Ross SE, Hurley JE, Hohenadel JM, Stoddart GL, Woodward CA, et al. Examining the Role of Health Services Research in Public Policy Making. Milbank Q. 2002;80:125-15431.

28. Arnold SR, Straus SE. Interventions to Improve Antibiotic Prescribing Practices in Ambulatory Care. Cochrane Database Syst Rev. 2005.

29. Kiesler DJ, Auerbach SM. Optimal Matches of Patient Preferences for Information, Decision-Making and Interpersonal Behavior: Evidence, Models and Interventions. Patient Educ Couns. 2006;61:319-341.

30. Oxman A, Lavis JN, Fretheim A. Use of Evidence in WHO Recommendations. Lancet. 2007;369:18831889

31. Wong SS, Lim SW, Quinlan KM. Integrity in and Beyond Contemporary Higher Education: What Does it Mean to University Students? Front Psychol. 2016;3(7):1094.

32. Page SA, Nyeboer J. Improving the Process of Research Ethics Review Research Integrity and Peer Review. 2017;2(1):14.

33. Sutton BP. The Effects of Technology in Society and Education: Education and Human Development. Master's Theses. 2013.

34. Oelke ND, Lima MADS, Acosta AM. Translação do Conhecimento: Traduzindo Pesquisa Para Uso na Prática e na Formulação de Políticas. Rev Gaúcha Enferm. 2015;36(3):113-117.

35. Hutchinson AM, Mallidou AA, Toth F, Cummings GG, Schalm C, Estabrooks CA. Review and Synthesis of Literature Examining Characteristics of Organizational Context that Influence Knowledge Translation in Healthcare: Technical Report Edmonton. Edmonton. University of Alberta, Faculty of Nursing; 2010.

36. Ward V, House A, Hamer S. Developing a Framework for Transferring Knowledge into Action: A Thematic Analysis of the Literature. Health Serv Res Policy. 2009;14(3):156-64. 